\title{
Supplementation of vitamins, probiotics and proteins on oxidative stress, enzymes and hormones in post-moult male broiler breeders
}

\author{
Rifat Ullah Khan', Zia Rahman², ljaz Javed ${ }^{3}$ and Faqir Muhammad ${ }^{3}$ \\ 'Department of Animal Health, Faculty of Animal Husbandary and Veterinary Science, University of Agriculture, \\ Peshawar, Pakistan, ${ }^{2}$ Subcampus Tobba Tek Singh, University of Agriculture, Faisalabad, Pakistan, ${ }^{3}$ Department of \\ Physiology and Pharmacology, University of Agriculture, Faisalabad, Pakistan
}

\begin{abstract}
This study was planned to investigate the comparative effect of vitamin $E$ and $C$, probiotics, protein level and the combination of these treatments on body weight, serum total antioxidant capacity (TAC), total oxidant status (TOS), oxidative stress index (OSI), aspartate aminotransferase (AST), alanine aminotransferase (ALT), triiodothyronine $\left(T_{3}\right)$, thyroxine $\left(T_{4}\right)$, cortisol and some minerals in $\mathrm{Zn}$-induced male broiler breeders. A total of 180 Hubbard male broiler breeders (65 weeks of age) were induced to moult. After moulting, the birds were randomly distributed into six groups. One group was fed vitamin $E(100 \mathrm{lU} / \mathrm{kg}$ feed), second group was fed vitamin C (500 IU/ $\mathrm{kg}$ feed), third group was fed probiotics $(50 \mathrm{mg} / \mathrm{L})$, fourth group was fed lower protein level ( $14 \%$ crude protein) and the fifth group was fed the combination of the mentioned treatments. The sixth group served as control. The results revealed that serum TAC significantly increased $(P<0.05)$ while TOS and OSI decreased $(P<0.05)$ in the vitamin $E$ fed group compared to the other treated groups. The analyses of the samples indicated that AST and ALT decreased significantly in the vitamin E supplemented group while $\mathrm{T}_{3}$ and $\mathrm{T}_{4}$ increased significantly as a result of this treatment. Cortisol concentration decreased significantly in the vitamin E fed group. Serum Mg increased significantly in the vitamin $E$ supplemented group. The results indicated that the physiological biochemistry disrupted in male breeders as a consequence of moulting could be compensated by feeding vitamin $\mathrm{E}$.
\end{abstract}

Keywords: Moulting, male broiler breeders, vitamins, probiotics, oxidative stress

Archiv Tierzucht 56 (2013) 61, 607-616

doi: 10.7482/0003-9438-56-061

Corresponding author:

Zia Rahman; email: drziar@yahoo.com

Department of Physiology and Pharmacology, University of Agriculture, Jail Road, Faisalabad, Pakistan

(c) 2013 by the authors; licensee Leibniz Institute for Farm Animal Biology (FBN), Dummerstorf, Germany.

This is an Open Access article distributed under the terms and conditions of the Creative Commons Attribution 3.0 License (http://creativecommons.org/licenses/by/3.0/).
Received: 3 Dezember 2012 Accepted: 14 March 2013 Online: 26 April 2013 
Abbreviations: ALT: alanine aminotransferase; AST: aspartate aminotransferase; CP: crude protein; OSI: oxidative stress index; T3: triiodothyronine; T4: thyroxine; TAC: total antioxidant capacity; TOS: total oxidant status

\section{Introduction}

Force moulting is an economical practice which enhances the productive and reproductive life span of the birds. This process has been associated with sudden change in physiological biochemistry (Berry 2003, Khan et al. 2011) which requires restoration before coming into production. Forced moulting has been conducted by a variety of techniques including fasting, photoperiod reduction or combination of both, hormone administration, feeding dietary salt of zinc, aluminium and iodine (Berry 2003, Park et al. 2004, Khan et al. 2011). The most important advantage of forced moulting is the rejuvenation of the reproductive system which originates from increased tissue efficiency, gonadal development, loss of adipose tissue, redevelopment of organs and tissue and hence better post-moult performance is achieved (Berry 2003, Park et al. 2004).

The level of crude protein (CP) is very important to control the body weight of broilers and male broiler breeders for optimum semen production (Zhang et al. 1999, Laudadio et al. 2012). Further, it has been commonly accepted that fertility of male broiler breeders could be maintained or can be raised by a lower CP level than those obtained with the level of $15-18 \%$ CP (Wilson et al. 1971). The reported adverse effect of high CP has been explained by the increased production of uric acid due to more excretion of nitrogen from the excess protein catabolism (Wilson et al. 1987).

Probiotics are live microbial cultures which leave beneficial effect on the host body by balancing the intestinal micro flora (Fuller 1989, Houndonougbo et al. 2011, Dibaji et al. 2012). They may be bacteria, fungi or yeas, and they are isolated from the gut of the same organism to which the probiotics are administered (Fox 1988, Yoruk et al. 2004, O'Dea et al. 2006, Ayed $\&$ Ghaoui 2011). Probiotics and prebiotics have been successfully used to improve the health of the poultry to achieve better production (O'Dea et al. 2006, Li et al. 2008, Perić et al. 2010).

Vitamin C, also commonly known as ascorbic acid, is another important antioxidant. Although birds synthesise vitamin $C$ in their body, however, its supplementation in the poultry diet has been recommended during stressful conditions (Khan et al. 2012a). Vitamin $\mathrm{E}$ is also a very important antioxidant which protects the body against the oxidative stress. Previously, we reported that reproductive efficiency of male broiler was improved as a result of vitamin E supplementation (Khan et al. 2012b). This vitamin is not synthesised by the birds and therefore, its inclusion in the feed cannot be avoided. We hypothesise that vitamin E may also have some role in the improved physiological biochemistry.

Therefore, the purpose of this study was to find the effectiveness of vitamins, probiotics and lower protein level on the amelioration of some physiological parameters associated with stress in moulted cockerels. 


\section{Material and methods}

\section{Experimental design and feeding of birds}

One hundred and eighty Hubbard male broiler breeders at the age of 65 weeks were induced to moult after acclimatisation for one week, during which they were fed a ration having $16 \%$ CP and lighting schedule was maintained at 16 hours per day. At the beginning of the second week, birds were subjected to moult with $\mathrm{ZnO}$ at the rate of $3000 \mathrm{mg} / \mathrm{kg}$ of feed with a moderate decrease in lighting schedule from 16 to $12 \mathrm{~h}$ and they were offered $50 \mathrm{~g} /$ bird feed on the daily basis (Khan et al. 2012b). The phase of moulting continued for five weeks until $20 \%$ reduction of their body weight was achieved. After completion of moulting birds were randomly assigned to six groups (five replicates per group) in a completely randomised design. Birds were reared on floor pens $(3.96 \times 3.96 \mathrm{~m})$ in a window sided house with controlled temperature, ventilation and illumination. One group was kept as control (CP-16\%), second group was fed vitamin E (CP-16\%+100 lU/kg of feed DL- a-tocopherol), third group vitamin C (CP-16\%+500 IU/L of water L-ascorbic acid), fourth group probiotics (CP-16\%+50 mg/L of water probiotics; Protexin, HiltonPharma, The Netherlands), fifth group lower protein level (CP-14\%) and the last group was fed the combination of vitamin $\mathrm{E}, \mathrm{C}$, protein and probiotics (CP-14\% +100 IU DL- a-tocopherol $/ \mathrm{kg}$ feed+500 IU L-ascorbic acid/L water+50 mg probiotics/L water) for five weeks. The detailed diet composition is reported in Table 1. Each bird was offered $140 \mathrm{~g} /$ day feed. The experiment lasted ten weeks after initiation of moulting. All animal procedures of this experiment were conducted in compliance with protocols approved by the Use and Care Committee, University of Agriculture, Faisalabad, Pakistan.

\section{Blood collection}

For determination of serum TAC, TOS, enzymes, hormones and minerals, about five ml blood samples from six birds per group were randomly taken by cervical dislocation. The blood samples were collected in sterile test tubes by decapitating the birds. Serum was separated after centrifugation the blood at $800 \times \mathrm{g}$ for $15 \mathrm{~min}$. Serum was collected in the small clean appendix for each sample and stored at $-20^{\circ} \mathrm{C}$ until further analyses. All samples were analysed in duplicate.

\section{Determination of serum TAC, TOS and OSI}

Total antioxidant capacity was measured in serum samples by using a novel automated method developed by Erel (2004), using o-dianisidine dihydrochloride (Sigma Chemical Co., London, UK) as a substrate. Total oxidant status of serum samples was determined by a new calorimetric measurement method described by Erel (2005). This assay is based on the oxidation of the ferrous into the ferric ions in the presence of various oxidant species, which are measured spectrophotometrically. The OSI, an indicator of the degree of oxidative stress, was calculated (TOS/TAS) $\times 100$ as described by Verit et al. (2006). 
Table 1

Ingredient and chemical composition of basal diet fed to broiler breeders

\begin{tabular}{lcc}
\hline Ingredients, g/kg & CP-16\% & CP-14\% \\
\hline Yellow corn & 430.0 & 450.0 \\
Canola meal & 170.0 & 180.0 \\
Rice polishing & 140.0 & 150.0 \\
Rice tips & 120.0 & 120.0 \\
Soybean meal & 60.0 & 20.0 \\
Maize gluten & 50.0 & 50.0 \\
Dicalcium phosphate & 10.0 & 10.0 \\
Lime stone & 10.0 & 10.0 \\
Vitamin minerals premix & 5.0 & 5.0 \\
Methionine & 2.5 & 2.5 \\
Lysine & 2.4 & 2.4 \\
Salt & 0.1 & 0.1 \\
Calculated composition & & \\
Crude protein, g/kg & 160.2 & 140.2 \\
Crude fibre, g/kg & 50.5 & 50.5 \\
Ash, g/kg & 70.0 & 50.0 \\
ME, MJ/kg & 12.24 & 12.22 \\
\hline Provid per kg & & \\
\hline
\end{tabular}

*Provided per kg of diet: Mn $80 \mathrm{mg}$; Zn $60 \mathrm{mg}$; Fe $60 \mathrm{mg}$; Cu $5 \mathrm{mg}$; Co $0.2 \mathrm{mg}$; I mg; Se $0.15 \mathrm{mg}$; choline chloride $200 \mathrm{mg}$; vitamin A (retinol) $12000 \mathrm{IU}$; vitamin D3 (cholecalciferol) $2400 \mathrm{IU}$; vitamin E (DL-a-tocopherol) $50 \mathrm{IU}$; vitamin $\mathrm{K}$ (menadione) $4 \mathrm{mg}$; vitamin B1 (thiamine) $3 \mathrm{mg}$; vitamin B2 (riboflavin) $6 \mathrm{mg}$; vitamin B5 (pantothenic acid) $25 \mathrm{mg}$; vitamin B6 (pyridoxine) $5 \mathrm{mg}$; vitamin B12 (cyanocobalamin) $0.03 \mathrm{mg}$; folic acid $1 \mathrm{mg}$

\section{Determination of serum enzymes and hormones}

Serum AST and ALT were measured spectrophotometrically (Biosystem, BTS-330, S.A. Costa Brava, Barcelona, Spain) using a commercially available kit (BT29 4 QY, Randox Laboratories Ltd., UK). Serum $\mathrm{T}_{3}$ was measured by JD Biotech (Roseto degli Abruzzi, Italy) in vitro diagnostic $\mathrm{T}_{3}$ EIA kit. The quantitative concentration of $\mathrm{T}_{4}$ was determined by JD Biotech, Roseto degli Abruzzi, Italy) in vitro diagnostic $\mathrm{T}_{4}$ ElA kit. The cortisol concentration in the samples was determined by using DRG (DRG Instruments GmbH, Marburg, Germany) ELISA kit. These hormones were measured using Stat Fax 303, ELISA reader at 450/620 nm.

\section{Mineral determination}

The preparation of serum samples for mineral analysis was carried out as described by Khan et al. (2012b). Briefly, the serum sample of $1 \mathrm{ml}$ was taken into a digestion flask and added $10 \mathrm{ml}$ concentrated nitric acid. The mixture was placed on a hot plate until all the fumes were evaporated. The flask was removed and cooled for $5 \mathrm{~min}$. After cooling, $5 \mathrm{ml}$ perchloric acid was added into the flask and heated the mixture again on a hot plate. When the volume was reduced to $1-2 \mathrm{ml}$, the flask was removed and the content was cooled again. The contents were diluted with $50 \mathrm{ml}$ deionize water, filtered and kept in a clean bottle until analysis. 
First standard solutions were run followed by samples. The concentration of minerals in the samples was obtained from the absorbance of standards and their corresponding concentrations (Khan et al. 2012b). Concentration of $\mathrm{Na}$ and $\mathrm{K}$ was measured using a flame photometer, while $\mathrm{Ca}$ and $\mathrm{Mg}$ concentrations were measured with the help of atomic absorption spectrophotometer.

\section{Statistical analysis}

Data was statistically analysed with the help of a statistical software SPSS v. 12.0 (SPSS Inc., Chicago, IL, USA). One-way analysis of variance was used to test the significance of treatment (six dietary treatments) on the studied traits (Steel et al. 1997). Means of the significantly affected traits were separated by Duncan Multiple Range Test (Duncan 1955). $P$-value less than 0.05 was considered to be statistically significant.

\section{Results}

In the present study, there was no significant difference between control and treated groups after moulting (Figure 1). The mean values of TAC, TOS and OSI have been presented in Table 2. Mean TAC was significantly higher in the vitamin $E$ group compared to the rest of the groups at the end of the experiment. On the contrary, mean TOS was the highest $(P<0.05)$ in the control group and lowest $(P<0.05)$ in the vitamin $E$ group. The vitamin $E$ supplemented group also registered significantly higher $(P<0.05)$ OSI compared to the other groups.

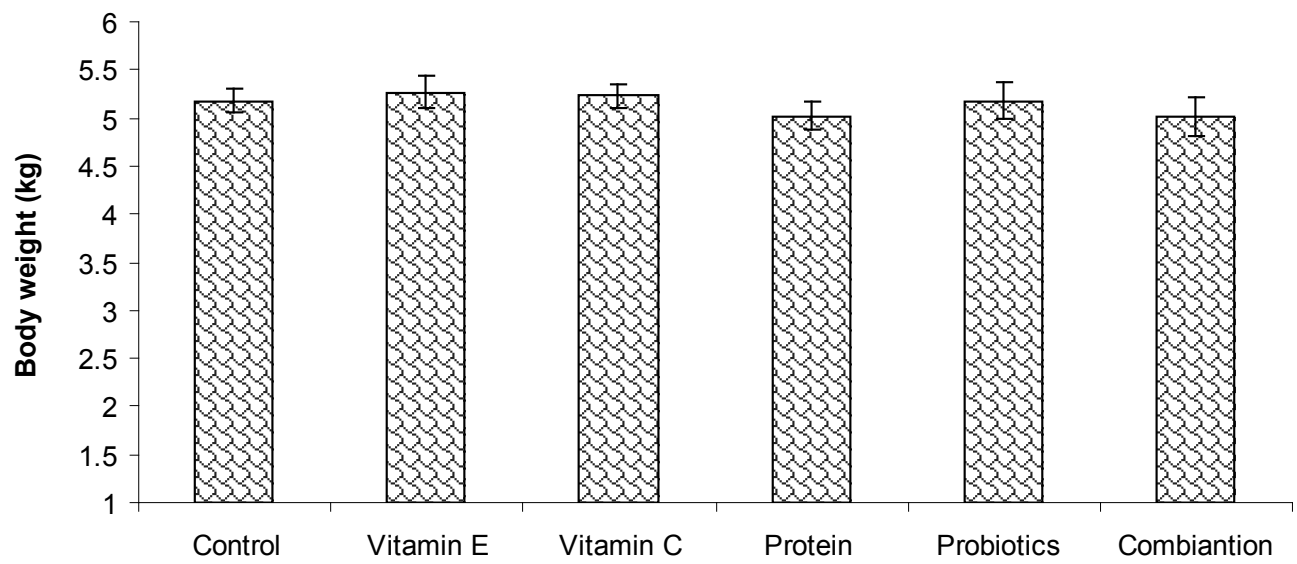

Figure1

Mean body weight of control and treated groups $(P>0.05)$

As shown in Table 3, mean AST and ALT decreased significantly $(P<0.05)$ in the vitamin $C$ supplemented group while $\mathrm{T}_{3}$ and $\mathrm{T}_{4}$ concentration increased significantly $(P<0.05)$ as a result of this treatment. The cortisol concentration decreased significantly $(P<0.05)$ in the vitamin E fed group. No significant change was observed in the mineral concentration except $\mathrm{Mg}$ which increased significantly $(P<0.05)$ in the vitamin E supplemented group (Table 4). 
Table 2

Mean TAC, TOS and OSI of post moult control and experimental male broiler breeders

\begin{tabular}{|c|c|c|c|}
\hline Groups & $\begin{array}{c}\text { TAC } \\
\text { (mmol Trolox equiv./L) }\end{array}$ & $\begin{array}{c}\text { TOS } \\
\left.\text { ( } \mu \mathrm{mol} \mathrm{H}_{2} \mathrm{O}_{2} \text { equiv. } / \mathrm{L}\right)\end{array}$ & OSI \\
\hline Control & $1.03 \pm 0.09^{B}$ & $1.40 \pm 0.05^{\mathrm{A}}$ & $143 \pm 9.87^{A}$ \\
\hline Vitamin E & $1.59 \pm 0.13^{\mathrm{A}}$ & $0.97 \pm 0.04^{\mathrm{D}}$ & $58.75 \pm 9.54^{\mathrm{E}}$ \\
\hline Vitamin C & $1.26 \pm 0.11^{\mathrm{B}}$ & $1.11 \pm 0.11^{\mathrm{CD}}$ & $80.45 \pm 3.23^{\mathrm{D}}$ \\
\hline Protein & $1.26 \pm 0.19^{B}$ & $1.16 \pm 0.05^{B C}$ & $83.45 \pm 5.32^{\mathrm{D}}$ \\
\hline Probiotics & $1.11 \pm 0.05^{\mathrm{B}}$ & $1.32 \pm 0.06^{\mathrm{AB}}$ & $100.34 \pm 9.87^{D}$ \\
\hline Combination & $1.20 \pm 0.08^{B}$ & $1.25 \pm 0.14^{\mathrm{BC}}$ & $95.47 \pm 12.34$ \\
\hline
\end{tabular}

Control: 16\% CP; Vitamin E: 16\% CP + 100IU/kg DL-a-tocopherol acetate; Vitamin C: 16\% CP + 500IU/kg L-ascorbic acid; Protein: $14 \%$ CP; Probiotics: $16 \%$ CP $+50 \mathrm{mg}$ probiotics (Lactobacillus plantarum, L. bulgaris, L. acidophilus, L. rhamnosus, Bifadobacterum binfadum, Streptococus thermophilus, Enterococus faecium, Aspergillus oryzae, Candida pintolopesi); Combination: $14 \% \mathrm{CP}+100 \mathrm{mg}$ vitamin $\mathrm{E}+500 \mathrm{mg}$ vitamin $\mathrm{C}+50 \mathrm{mg}$ probiotics, ${ }^{\mathrm{A}-\mathrm{D}}$ Mean values within a column, not bearing a common superscript differ significantly $(P \leq 0.05)$

Table 3

Mean AST, ALT, T3, T4 and cortisol of post moult control and experimental male broiler breeders

\begin{tabular}{lccllc}
\hline Groups $^{*}$ & $\mathrm{AST}, \mathrm{U} / \mathrm{L}$ & $\mathrm{ALT}, \mathrm{U} / \mathrm{L}$ & $\mathrm{T}_{3^{\prime}} \mathrm{ng} / \mathrm{mL}$ & $\mathrm{T}_{4^{\prime}} \mu \mathrm{g} / \mathrm{dL}$ & Cortisol, ng/mL \\
\hline Control & $40.28 \pm 1.87^{\mathrm{AB}}$ & $11.95 \pm 0.43^{\mathrm{A}}$ & $3.34 \pm 0.10^{\mathrm{C}}$ & $5.90 \pm 0.10^{\mathrm{E}}$ & $42.19 \pm 1.71^{\mathrm{A}}$ \\
Vitamin E & $36.86 \pm 1.69^{\mathrm{BC}}$ & $7.29 \pm 0.30^{\mathrm{B}}$ & $3.77 \pm 0.12^{\mathrm{AB}}$ & $6.46 \pm 0.20^{\mathrm{CD}}$ & $37.46 \pm 1.33^{\mathrm{B}}$ \\
Vitamin C & $30.44 \pm 1.17^{\mathrm{D}}$ & $5.49 \pm 0.22^{\mathrm{C}}$ & $4.02 \pm 0.12^{\mathrm{A}}$ & $8.28 \pm 0.18^{\mathrm{A}}$ & $40.69 \pm 1.62^{\mathrm{AB}}$ \\
Protein & $35.82 \pm 1.19^{\mathrm{C}}$ & $7.22 \pm 0.33^{\mathrm{B}}$ & $3.39 \pm 0.22^{\mathrm{C}}$ & $6.22 \pm 0.38^{\mathrm{DE}}$ & $41.90 \pm 1.46^{\mathrm{AB}}$ \\
Probiotics & $41.81 \pm 1.02^{\mathrm{A}}$ & $11.16 \pm 0.53^{\mathrm{A}}$ & $3.63 \pm 0.18^{\mathrm{BC}}$ & $6.87 \pm 0.36^{\mathrm{BC}}$ & $42.68 \pm 1.65^{\mathrm{A}}$ \\
Combination & $35.94 \pm 1.25^{\mathrm{C}}$ & $6.24 \pm 0.31^{\mathrm{BC}}$ & $3.86 \pm 0.21^{\mathrm{AB}}$ & $6.98 \pm 0.27^{\mathrm{B}}$ & $38.46 \pm 1.45^{\mathrm{AB}}$ \\
\hline
\end{tabular}

${ }^{*}$ Dietary treatments: see Table 2, A,BMean values within a column, not bearing a common superscript differ significantly $(P \leq 0.05)$

Table 4

Mean $\mathrm{Na}, \mathrm{K}, \mathrm{Ca}$ and $\mathrm{Mg}$ of post moult control and experimental male broiler breeders

\begin{tabular}{lcccc}
\hline Groups & $\mathrm{Na}(\mathrm{mg} / \mathrm{L})$ & $\mathrm{K}(\mathrm{mg} / \mathrm{L})$ & $\mathrm{Ca}(\mathrm{mg} / \mathrm{L})$ & $\mathrm{Mg}(\mathrm{mg} / \mathrm{L})$ \\
\hline Control & $2083.05 \pm 137.70$ & $150.99 \pm 9.23$ & $168.41 \pm 12.98$ & $31.19 \pm 1.76^{\mathrm{BC}}$ \\
Vitamin E & $2267.90 \pm 90.20$ & $139.69 \pm 11.22$ & $225.23 \pm 20.17$ & $37.03 \pm 1.54^{\mathrm{A}}$ \\
Vitamin C & $2143.40 \pm 57.05$ & $148.25 \pm 11.51$ & $189.36 \pm 15.12$ & $36.03 \pm 1.14^{\mathrm{AB}}$ \\
Protein & $2255.00 \pm 99.10$ & $148.34 \pm 8.48$ & $206.11 \pm 19.54$ & $35.06 \pm 1.74^{\mathrm{A}-\mathrm{C}}$ \\
Probiotics & $1894.55 \pm 96.55$ & $134.98 \pm 8.39$ & $178.38 \pm 12.13$ & $29.62 \pm 0.79^{\mathrm{C}}$ \\
Combination & $2036.55 \pm 93.70$ & $148.15 \pm 7.93$ & $202.14 \pm 22.61$ & $31.15 \pm 1.36^{\mathrm{BC}}$ \\
\hline
\end{tabular}

${ }^{*}$ Dietary treatments: see Table 2, ${ }^{A-C}$ Mean values within a column, not bearing a common superscript differ significantly $(P \leq 0.05)$.

\section{Discussion}

In the present study, the body weight did not change as a result of different supplements; however, TAC was significantly high in the vitamin E supplemented group. Previously, we 
reported that an exogenous supplementation of antioxidants can ameliorate the injury of free radicals in the body (Khan 2011). Total antioxidant capacity is a summary variable of the different factors that measures the ability of serum to inhibit oxidative stress (Erel 2004, Khan 2011). Vitamin $E$ is a potent antioxidant which directly scavenges the free radicals and regulates the activities of the antioxidant system (Khan et al. 2011). Sahin et al. (2004) reported that supplementation of melatonin, which is considered as a potent antioxidant, improved the antioxidant status in the plasma of Japanese quails, exposed to heat stress. The present study confirmed the previous general findings that supplementation of vitamin E suppresses oxidative stress (Khan et al. 2011). The combined effect of vitamin E and C on TAC was not much pronounced in this study which is according to the previous reports (Chen 1981, Aburto \& Britton 1998). The discrepancy might be due to the dose of antioxidant vitamins or their interaction at the time of absorption and cellular level.

The TOS was significantly lower in the vitamin $E$ and $C$ groups compared to the other treatments. Oxidant molecules are produced endogenously by living organisms and these oxidants are neutralised via enzymatic and non-enzymatic antioxidants (Erel 2005, Khan et al. 2012). Oxidative stress develops as a consequence of the production of oxidants (Khan et al. 2011). The combined effect of oxidants can be measured collectively, which is quick and requires less labour (Erel 2005). In this study, we observed that the level of TOS was significantly higher in the absence of antioxidants (vitamin E and C). The lower TOS either in the vitamin $E$ and $C$ groups or higher TOS value in the control group are in agreement with detailed reports on TOS and TAC found by Erel (2005), Verit et al. (2006) and Verit et al. (2009). Upon supplementation of antioxidant vitamins, the production of corticosterone is depressed (Kucuck et al. 2003). In our study, the level of corticosterone was significantly decreased and we may speculate that the supplementation of vitamins at the present levels could have increased blood antioxidants and decreased corticosterone concentrations (Kucuck et al. 2003). By decreasing the synthesis of corticosteroids, antioxidant vitamins might have worked to alleviate the negative effects of stress, which might have resulted in less production of oxidants (Kucuck et al. 2003, Sahin et al. 2004). In the present study, the OSI was significantly low in the vitamin E supplemented group. Information on the OSI status in poultry is not available in the literature. However, reports on human studies indicate that the level of OSI is elevated in the condition of oxidative stress (Verit et al. 2006, 2009). The oxidative stress index gives an accurate measurement of oxidative stress and higher level of OSI indicates high oxidative stress (Verit et al. 2009). Moreover, this index is a reliable indicator and minimises the variability of individual parameters of oxidative stress (Verit et al. 2009).

To the best of our knowledge, it has not been reported on the serum biochemistry in moulted birds. In this study, serum AST and ALT decreased significantly in the vitamin E fed group. Lower AST and ALT levels are the indicator of better health in animals. According to Peric et al. (2009) the determination of AST and ALT is an indicator of oxidative damage in liver tissue and the elevated level of these enzymes is usually associated with liver diseases. In a study, Gursu et al. (2004) reported that serum ALT and AST decreased in response to vitamin C $(250 \mathrm{mg} / \mathrm{kg})$ in heat stressed Japanese quail. Jayasree et al. (2003) reported that the supplementation of vitamin $E$ at the rate of $300 \mathrm{mg} / \mathrm{kg}$ reduced the AST and ALT concentrations which were increased in response to deltamethrin toxicity in broiler chicks. Perić et al. (2009) found a significant reduction in ALT and AST enzymes activities 
in broiler chicks fed $0.3 \mathrm{ppm}$ selenium and suggested that this reduction was due to the antioxidative effect of selenium. Sahin et al. (2001) reported that $250 \mathrm{mg} / \mathrm{kg}$ a-tocopherol acetate decreased serum AST and ALT in broilers reared under heat stress $\left(32^{\circ} \mathrm{C}\right)$. Franchini et al. (1995) also noted that the AST level increased with vitamin E supplementation in young turkey; however, it decreased in old turkey (140 days old) which is quite consistent to our study. In this study, the reduction of serum AST and ALT seemed to be due to the antioxidant effect of vitamin E supplementation.

In this study, the serum thyroid hormone concentration significantly increased in the vitamin E supplemented group. Thyroid hormones are well known to regulate energy metabolism, accelerate basal and oxidative metabolism rate by increasing the respiratory rate, mitochondrial mass and mitochondrial cytochrome contents of the cell (Lin et al. 2001). The plasma level of thyroid hormones changes with age, fasting, temperature, feeding and pathophysiology (Lin et al. 2001). It has been suggested that a decreased thyroid hormone level results in failure to provide adequate oxygen delivery to the tissues that may lead to hypoxia, heart failure and ascites (Hassanzadeh 2009). Nockles \& Carnevale (1988) concluded that $\mathrm{T}_{3}$ and $\mathrm{T}_{4}$ values were not influenced by the amount of feed consumed, body weight or blood fluid volume in fasted male White Leghorn cockerels. Sahin et al. (2002) observed a linear increase in serum $T_{3}$ and $T_{4}$ concentrations in response to graded level of vitamin $E$ in Cobb male broilers reared under heat stress.

In the current study, the serum concentration of cortisol was significantly low in the vitamin E fed group. Increased circulating level of corticosterone has been associated with stress response in poultry birds (Onbasilar \& Erol 2007). The high level of corticosterone has been linked with deleterious effects on bird's performance. Upon the exposure to stress, hypothalamic-pituitary adrenal system is activated, which stimulates the hypothalamus to cause the pituitary gland to release adrenocarticotropic hormone (ACTH). The ACTH in the blood activates adrenal to secrete corticosterone (Virden et al. 2007). Satterlee et al. (1989) concluded that ascorbic acid reduced plasma corticosterone in broiler chickens prior to slaughter. Taniguchi et al. (2007) reported on chickens that vitamin E at the level of 500 and $5000 \mathrm{mg} / \mathrm{kg}$ markedly decreased serum corticosterone concentration as well as the level of adrenal free cholesterol and concluded that vitamin E suppresses serum corticosterone by inhibiting the conversion of cholesterol esters to free cholesterol in the adrenal gland.

In this study, no significant difference was found in serum mineral concentration except $\mathrm{Mg}$, where, it increased significantly in the vitamin E supplemented group. The Mg is a cofactor of several enzyme systems, where, thymine pyrophosphate is an essential component. Magnesium is necessary for the proper functioning of oxidative phosphorylation. Magnesium deficient diet leads to poor growth, decreased muscle tone, incoordination and ataxia (Merck 1986). Moreover, it is involved in the synthesis and degradation of DNA and plays a key-role in the immune system and neurotransmission (Sahin et al. 2005). It is well documented that Mg plays a significant role in attenuation of free radicals either by preventing the production of free radicals or by facilitating the scavenging of free radicals (Garcia et al. 1998). Magnesium deficiency elevates lipid peroxidation of hepatic tissue, although the mechanism of action is not clearly understood (Sahin et al. 2005). Guo et al. (2003) reported that Mg elevates significantly the activity of hepatic catalase and improves the antioxidant capacity of broilers. The role of vitamin $\mathrm{E}$ in elevation of $\mathrm{Mg}$ is still to be elucidated. 
From the findings of the present study, it can be concluded that for an early recovery from the moulting stress, vitamin E could be supplemented in the diet of moulted broiler breeders.

\section{References}

Aburto A, Britton WM (1998) Effects of different levels of vitamins A and E on the utilization of cholecalciferol by broiler chickens. Poult Sci 77, 570-577

Ayed MH, Ghaoui F (2011) Efficiency of supplementing saccharomyces cerevisiae var. ellipsoideus for improved growth performance and carcass yield in broilers. Res Opin Anim Vet Sci 1, 371-374

Berry WD (2003) The physiology of induced molting. Poult Sci 82, 971-980

Chen LH (1981) An increase in vitamin E requirement induced by high supplementation of vitamin $\mathrm{C}$ in rats. Am J Clin Nutr 34, 1036-1041

Dibaji SM, Seidavi A, Asadpour L (2012) Effect of dietary inclusion of the synbiotic Biomin IMBO on broilers' some blood metabolites. Res Opin Anim Vet Sci 2, 10-13

Duncan DB (1955) Multiple range and multiple F-test. Biometrics 11, 1-42

Erel $O$ (2004) A novel automated method to measure total antioxidant response against potent free radical reactions. Clin Biochem 37, 112-119

Erel $O$ (2005) A new automated colorimetric method for measuring total oxidant status. Clin Biochem 38, 1103-1111

Fox SM (1988) Probiotics: intestinal inoculants for production animals. Vet Med 83, 806-830

Franchini A, Bertuzzi S, Tosarelli C, Manfreda G (1995) Vitamin E in Viral Inactivated Vaccines. Poult Sci 74, 666-671

Fuller R (1989) Probiotics in man and animals. J Appl Bacteriol 66, 365-378

Garcia LA, DeJong SC, Martin SM, Smith RS, Buettner GR, Kerber RE (1998) Magnesium reduces free radicals in an in vivo coronary occlusion-reperfusion model. J Am Coll Cardiol 32, 536-539

Guo Y, Zhang G, Yuan J, Nie W (2003) Effects of source and level of magnesium and vitamin E on prevention of hepatic peroxidation and oxidative deterioration of broiler meat. Anim Feed Sci Technol 107, 143-150

Gursu MF, Onderci M, Gulcu F, Sahin K (2004) Effects of vitamin C and folic acid supplementation on serum paraoxonase activity and metabolites induced by heat stress in vivo. Nutr Res 24, 157-164

Hassanzadeh M (2009) New approach for the incidence of ascitis syndrome in broiler chickens and management control the metabolic disorders. Int J Poult Sci 8, 90-98

Houndonougbo MF, Chrysostome CAAM, Amoussa ZLAO (2011) Tchoukoutou residue and yogurt as feed additives in broilers feed. Res Opin Anim Vet Sci 1, 597-600

Jayasree U, Gopala Reddy A, Reddy KS, Anjaneyulu Y, Kalakumar B (2003) Evaluation of vitamin E against deltamethrin toxicity in broiler chicks. Indian J Physiol Pharmacol 47, 447-452

Khan RU (2011) Antioxidants and poultry semen quality. Worlds Poult Sci J 67, 297-308

Khan RU, Nikousefat Z, Javdani M, Tufarelli V, Laudadio V (2011) Zinc-induced moulting: production and physiology. Worlds Poult Sci J 67, 497-506

Khan RU, Naz S, Nikousefat Z, Selvaggi M, Laudadio V, Tufarelli V (2012a) Effect of ascorbic acid in heat-stressed poultry. Worlds Poult Sci 68, 477-490

Khan RU, Rahman ZU, Javed I, Muhammad F (2012b) Effects of Vitamins, Probiotics, and Protein Level on Semen Traits and Some Seminal Plasma Macro- and Microminerals of Male Broiler Breeders After ZincInduced Molting. Biol Trace Elem Res 148, 44-52

Kucuk O, Sahin N, Sahin K (2003) Supplemental zinc and vitamin A can alleviate negative effects of heat stress in broiler chickens. Biol Trace Elem Res 94, 225-235

Laudadio V, Passantino L, Perillo A, Lopresti G, Passantino A, Khan RU, Tufarelli V (2012) Productive performance and histological features of intestinal mucosa of broiler chickens fed different dietary protein levels. Poult Sci 91, 265-270 
Li X, Qiang L, Xu L, Xu C (2008) Effect of Supplementation of Fructooligosaccharide and/or Bacillus Subtilis to Diets on Performance and on Intestinal Microflora in Broilers. Arch Tierz 51, 64-70

Lin DS, Connor WE, Wolf DP, Neuringer M, Hachey DL (1993) Unique lipids of primate spermatozoa: desmosterol and docosahexaenoic acid. J Lipid Res 34, 491-499

Merck (1986) The Merck veterinary manual: a handbook of diagnosis, therapy, and disease prevention and control for the veterinarian. 6th ed., Merck, Rahway, NJ, USA

Nockels CF, Carnevele J, Ewing D (1988) Effect of refeeding fasted chicks on serum thyroid hormones. Nutr Res 8, 95-98

O'Dea EE, Fasenko GM, Allison GE, Korver DR, Tannock GW, Guan LL (2006) Investigating the Effects of Commercial Probiotics on Broiler Chick Quality and Production Efficiency. Poult Sci 85, 1855-1863

Onbasilar EE, Erol H (2007) Effects of different forced moulting methods on post moult production, corticosterone level, and immune response to sheep red blood cells in laying hens. J Appl Poult Res 16, 529-536

Park SY, KIM WK, Birkhold SG, Kubena LF, Nisbet DJ, Ricke SC (2004) Induced moulting issues and alternative dietary strategies for the egg industry in the United States. Worlds Poult Sci J 60, 196-209

Peric L, Milosevic N, Zikic D, Bjedov S, Cvetkovic D, Markov S, Mohnl M, Steiner T (2010) Effect of probiotic and phytobiotic products on performance, gut morphology and cecal microflora of broiler chicks. Arch Tierz 53, 350-359

Sahin K, Onderci M, Gursu MF, Kucuk O, Sahin N (2004) Effect of Melatonin Supplementation on Biomarkers of Oxidative Stress and Serum Vitamin and Mineral Concentrations in Heat-Stressed Japanese Quail. J Appl Poult Res 13, 342-348

Sahin K, Smith MO, Onderci M., Sahin N, Gursu MF, Kucuk O (2005) Supplementation of zinc from organic or inorganic source improves performance and antioxidant status of heat-distressed quail. Poult Sci 84, 882-887

Sahin K, Sahin N, Onderci M, Yaralioglu S, Kucuk O (2001) Protective role of supplemental vitamin E on lipid peroxidation, vitamins $\mathrm{E}, \mathrm{A}$ and some mineral concentrations of broilers reared under heat stress. Vet Med Czech 46, 140-144

Sahin K, Kucuk O, Sahin N, Sari M (2002) Effects of vitamin C and vitamin E on lipid peroxidation status, serum hormone, metabolite, and mineral concentrations of Japanese quails reared under heat stress $\left(34^{\circ} \mathrm{C}\right)$. Int $J$ Vitam Nutr Res 72, 91-100

Satterlee DG, Aguilera-Quintana I, Munn BJ, Krautmann BA (1989) Vitamin C amelioration of the adrenal stress response in broiler chickens being prepared for slaughter. Comp Biochem Physiol A Physiol 94, 569-574

Steel RGD, Torrie JH, Dickey DA (1997) Principles and Procedures of Statistics. 3rd ed. McGraw-Hill, New York, USA

Taniguchi N, Ohtsuka A, Hayashi K (2001) A high dose of vitamin E inhibits adrenal corticosterone synthesis in chickens treated with ACTH. J Nutr Sci Vitaminol (Tokyo) 47, 40-46

Verit FF, Verit A, Ciftci H, Erel O, Çelik H (2009) Paraoxonase-1 Activity in Subfertile Men and Relationship to Sperm Parameters. J Androl 30, 183-189

Verit FF, Verit A, Kocyigit A, Ciftci H, Celik H, Koksal M (2006) No increase in sperm DNA damage and seminal oxidative stress in patients with idiopathic infertility. Arch Gynecol Obstet 274, 339-344

Virden WS, Lilburn MS, Thaxton JP, Corzo A, Hoehler D, Kidd MT (2007) The Effect of Corticosterone-Induced Stress on Amino Acid Digestibility in Ross Broilers. Poult Sci 86, 338-342

Wilson HR, Rowland Jr LO, Harms RH (1971) Use of low protein grower diets to delay sexual maturity of broiler breeder males. Br Poult Sci 12, 157-163

Wilson JL, McDaniel CD, Sutton CD (1987) Dietary Protein Levels for Broiler Breeder Males. Poult Sci 66, 237-242

Yoruk MA, Gul M, Hayirli A, Macit M (2004) The effects of supplementation of humate and probiotic on egg production and quality parameters during the late laying period in hens. Poult Sci 83, 84-88

Zhang X, Berry WD, McDaniel GR, Roland DA, Liu P, Calvert C, Wilhite R (1999) Body weight and semen production of broiler breeder males as influenced by crude protein levels and feeding regimens during rearing. Poult Sci 78, 190-196 